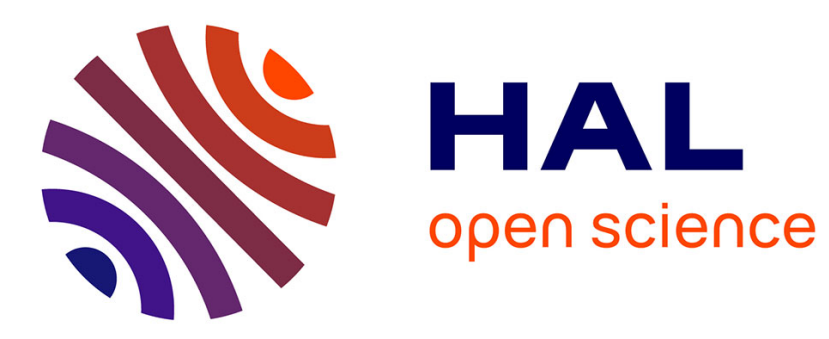

\title{
Professionalization in Safety: Creating Effective Learning Environments.
}

Christian Foussard, Wim van Wassenhove

\section{To cite this version:}

Christian Foussard, Wim van Wassenhove. Professionalization in Safety: Creating Effective Learning Environments.. 29th European Safety and Reliability Conference, 2019, Hanover, Germany. 10.3850/978-981-11-2724-3_0459-cd. hal-02305811

\section{HAL Id: hal-02305811 \\ https://hal.science/hal-02305811}

Submitted on 4 Oct 2019

HAL is a multi-disciplinary open access archive for the deposit and dissemination of scientific research documents, whether they are published or not. The documents may come from teaching and research institutions in France or abroad, or from public or private research centers.
L'archive ouverte pluridisciplinaire $\mathbf{H A L}$, est destinée au dépôt et à la diffusion de documents scientifiques de niveau recherche, publiés ou non, émanant des établissements d'enseignement et de recherche français ou étrangers, des laboratoires publics ou privés. 


\section{Christian FOUSSARD}

Consultant Risk Management \& Process Safety, Senior Lecturer, Dubai United Arab Emirates.

E-mail : christian.foussard@mines-paris.org

\section{Wim VAN WASSENHOVE, $\mathrm{PhD}$}

Assistant Professor, Centre de recherche sur les risques et les crises, MINES ParisTech-PSL Research University, France. E-mail : wim.van_wassenbove@mines-paristech.fr

Health, Safety, and Working Conditions Committees (CHSCT/CSE) play a major role in the day to day organization of companies and safety professionals have a crucial position in such meetings. It goes far beyond a set of regulatory knowledge and communication skills, but this unique atmosphere cannot be taught using classical academic lectures. In order to create an effective learning environment, the post master Management of Industrial Risks (MS MRI) from PSL University - Mines ParisTech, has successfully experimented for the last 3 years the use of role-playing games to allow students to embrace the inherent complexity of these type of committees.

In order to design effective learning environments, four perspectives have to be taken into account. Each of these perspectives are centered on respectively student, knowledge, assessment and community. The purpose is (1) to promote connections between acquired knowledge and current academic tasks, (2) to learn with understanding instead of simple acquisition of disconnected sets of facts and skills, (3) to provide feedback to students that give opportunities to challenge and improve their learning and (4) to provide affinity between the school and a larger professional community.

This paper describes how this curriculum has been designed, set and achieved. It involves the participation in the game play of several highly-experimented professionals: an occupational physician, an engineer and inspector from the Regional Retirement Insurance and Occupational Health Offices (CNAMTS), a labor inspector, a labor union representative, a paralegal and the director of the post-master himself. They are mixed with students that play not only safety professionals but various positions in the committee.

Results from surveys to assess this CHSCT game play experiment are presented and perspectives regarding innovative learning design for safety professionals are discussed.

Keywords: safety professional, working committee, occupational health, education, role playing game, adult learning

\section{Background}

In France, the Health, Safety, and Working Conditions Committee (CHSCT/CSE) is mandatory for upper tier Seveso establishments and for companies with 300 or more employees. (Art L. 2315-36, French Labor Code). For smaller enterprises, the labor inspector may impose the creation of a health, safety and working conditions commission when this measure is necessary, (art L. 2315-37, ibid). The commission is chaired by the employer and shall include at least three staff representatives. The CHSCT/CSE is expected to contribute to the promotion of health, safety and working conditions in the company (Art. L. 2312-9, ibid). The HSE manager participate in these meetings, in support of or as the representative of the Chief Executive Officer. Other actors are an occupational doctor, a labor inspector, prevention agents of social security organizations. They carry out an analysis of the occupational risks to which workers may be exposed, as well as the effects of exposure to occupational risk factors related to the prevention of arduousness.

\section{Educational Objectives}

The post master Management of Industrial Risks (MS MRI) from PSL University - Mines ParisTech, has grown in the last 14 years to be more and more professionalizing. A major guideline of MS MRI is to develop better education in risk management to bridge theoretical aspects to the professional real-life context (Van Wassenhove \& Foussard, 2018). The case of Health, Safety, and Working Conditions Committee (CHSCT/CSE) is quite an educational challenge regarding on the one hand, the crucial position of safety professionals in such meetings and on the other hand, operational and legal consequences on companies' activities. The pedagogical team conducted an in-depth analysis of these issues that lead to define the following educational objectives expressed in two areas of knowledge and two areas of skills (see Table1).

\section{Proceedings of the 29th European Safety and Reliability Conference.}

\section{Edited by Michael Beer and Enrico Zio}

Copyright (c) 2019 European Safety and Reliability Association.

Published by Research Publishing, Singapore.

ISBN: 978-981-11-2724-3; doi:10.3850/978-981-11-2724-3_0459-cd 
Table 1. Educational objectives associated to CHCST/CSE

K1: Understanding the regulatory framework, purpose, role and operation of a CHSCT/CSE

K2: Understanding the expectations and visions of the various participants

S1: Ability to lead and manage a meeting or an extraordinary session of the CHSCT/CSE

S2: Perform a pertinent argumentation and sustain discussion in order standing up for what one believes to be right.

\section{Selection and Design of Pedagogic Tools}

Requirements for a HSE professional training curriculum have been set considering that students getting their degree in HSE must be fully operational and demonstrate their professionalism when they start their first job (Wybo \& Van Wassenhove, 2016). Among other criteria, it involves a strong implication of safety professionals, the use of realistic case studies and interactions with industry practitioners. Learning environments are also a fundamental part of the learning process and are of key concern to teachers and students (Marsh, 2009). Among opportunities that education should offer, we do believe that one of the main is giving students the chance to practice a skill (Vos, 2015). In order to be efficient and accurate, capability to grasp connections between concepts is an essential skill. Moreover, students should establish their knowledge through action and gain that knowledge through experience (Siemens, 2004). CHSCT/CSE goes far beyond a set of regulatory knowledge and communication skills. To meet our educational goals, it is clear that the unique atmosphere of such committees cannot be taught using classical academic lectures. At this point, blended learning seemed to be an interesting option to consider. A strong body of evidence (Lee, 2010) regarding the teaching and learning outcomes from using simulation games gives enough confidence to consider that such a tool is adequate to meet criteria given by Bloom's taxonomy of educational objectives (Bloom,1956).

\section{Design of the Role-Playing Game}

\subsection{Planning \& script}

The purpose of planning is to determine a learning content in relation to the educational objectives targeted by the game, the capacities that will be acquired or consolidated are to be elicited. The type of information that should be conveyed and the principles the game should release are defined at this stage (Fripp, 1993). By specifying the content and pedagogical function of the game, a solid framework that guides the entire conceptualization of the game is set. Then, concepts that have been selected must be embodied into a script (Van Est \& al, 2011). According to the main elements of the game, chosen ideas are developed and pathways to enact them are explored. Considering that CHSCT/CSE duties apexes through dedicated meetings or extraordinary sessions, it has been agreed that the role-playing game would be built on the simulation of such a session. A first obvious benefit is that the duration of the exercise (i.e. based on a standard company's meeting) is compatible with real time playing. Thus, dynamics of interactions will be quite natural, roles of game masters will be adjusted to raise topics adequately and to bounce on the pertinent contribution of players. As the experience of CHSCT/CSE often deals significantly with emotional content, the choice of playing extraordinary sessions following two occupational accidents seemed to be adequate to bind commitment of future professionals. To successfully engage students with the game, a specific attention to the start-up has been paid. The use of movies edited by the French National Research and Safety Institute for the Prevention of Occupational Accidents and Diseases (INRS) allows a spirited launching within a short time frame (e.g. around 10 minutes).

\subsection{Validity of the role-playing game}

CHSCT/CSE game play is a modelling of specific situations of reality which are inherently complex. A pedagogical postulate is that those situations become fathomable when stripped of elements that make them fuzzy and highlights characteristics deemed important. The exercise is therefore a simplification to facilitate the analysis and understanding of the facts and behaviors that specifically constitute these type of committees (Greenblat, 1988). Furthermore, the simulation must be valid to gain some benefit. The validity of a simulation leans on its fidelity to represent reality. The couple realism/simplification has to be properly balanced as complexity engenders difficulties to create and use the simulation and eventually the subsequent learning (Norris, 1986). To fulfil those constrains, the selected solution relies on study cases that are based on accidents that really occurred. Narration of events is supported by two short movies edited by INRS. The first one highlights the multicausality of workplace accidents (i.e. combination of different factors such as organization of work, machine design, ...) and enhance the value of a comprehensive prevention approach. The second one illustrates how dysfunctions in a company can have tragic consequences on health and safety. 


\subsection{Game masters}

Literature (Hofstede et al., 2010; Tiwan, et al., 2014) concur that a poorly teaching team is a threat to student learning on simulations. The lack of knowledge from tutors, insufficient groundwork to appreciate the likely outcomes of various kinds of choices, inadequate management of stress or emotions and inaccurate feedback are the main factors that could have as a direct consequence that students would be unlikely to learn much. Also, the lecturer's temperament and style are decisive for the efficiency of the simulation (Baruch, 2006). In order to prevent these pitfall, a multidisciplinary team of highly-experimented professionals has been built around the director of the post-master. An occupational physician, an engineer and inspector from the Regional Retirement Insurance and Occupational Health Offices (CNAMTS), a paralegal and a labor union representative play their own role and assist students in the elaboration of each character involved in the session of the CHSCT/CSE. All of them have both a noteworthy proven-track record of contributions to $\mathrm{CHSCT} / \mathrm{CSE}$ of major organizations and substantial teaching experiences. This expertise is crucial to pledge validity of the simulation by (1) focusing on key points, (2) addressing a discourse fully in line with real conditions, (3) using tricky objections commonly used by stakeholders to stand up to opponents. Moreover, attitudes and behaviors (e.g. especially nonverbal communication), shaped by many years of companies' practices, give a fresh taste of reality to the experience.

\section{Outcomes}

\subsection{Assessment of competencies}

Assessments in higher education tends to fall within validity of evaluation instruments (Taras, 2002; Sambell et al., 2013). Many simulation assessments rely on the enthusiasm of students and teacher's perception as proof of the validity of the pedagogy (Burns et al. , 1990). It is still also uncertain whether what is learned from simulation can be effectively transferred to the working world (Anderson et al., 2009). Even if it counts for only a tiny piece of evidence, we mention that during the 3 years of experimentation of the CHSCT/CSE role play, the eagerness of the 95 students trained is undisputable. Additionally, feedback collected from the professionals is fairly outstanding and their renewed commitment illustrate their beliefs in the merits of the exercise. Although encouraging, these elements cannot be enough. Thus, a 5-level competency scale (see Table 2) has been set and for each area associated to educational objectives, the development of each student has been appraised and classified into one of the following categories: minimal, partial, acceptable, thorough, advanced. Several figures hereafter display the distribution of participants in each category ante and post simulation.

Table 2. Competency levels

\begin{abstract}
Advanced competency development (9-10)
Actively contributes in discussions on a broad range of topics, even when the subjects are less familiar. Builds on others' ideas by making links to outside references and experiences. Expresses thoughts effortlessly and uses an assortment of communication strategies as needed. Adjusts speed and streamlines language to take different audiences into account. Debates several aspects of problems and infers evidence by making links between ideas. Contributes to discussions by proposing ideas and opinions to peers. Adapts ideas and information from lectures to use in new contexts and uses accordingly to justify own opinions.
\end{abstract}

\section{Thorough competency development (7-8)}

Contributes in all types of situations needing interaction. Participates in discussions by volunteering opinions and information, expanding on ideas, asking questions and providing details. Supports or refutes alternatives on topics with facts and examples. Confirms and accommodates own understanding or that of others by rephrasing and reformulating messages and enquiring for clarification. Elaborates on ideas using an expanded set of concepts, with reasonable confidence. Uses a variety of available resources and finds pertinent information in lectures to support understanding and asks questions to further own understanding. Selects data found in lectures to use in a new context and organizes this. Builds on elements in lectures to carry out tasks (e.g. proposing plausible solutions to a problem) and uses familiar strategies as needed.

\section{Acceptable competency development (5-6)}

Contributes in discussions on acquainted topics, taking turns and sustaining interactions, but requires some support to elaborate on complex ideas. Needs to be prompted to contribute to discussions on less familiar matters. Verifies own understanding by asking for clarification, asking questions and repeating a message. Corrects when prompted, some mistakes that may impede understanding when communicating more elaborate thoughts. Appropriately selects and uses available resources and uses various components of lectures to build understanding. Demonstrates understanding of simple concepts, but needs support to express understanding of overall meaning of situation. Uses, when reminded, strategies that have been taught.

\section{Partial competency development (3-4)}

Contributes to discussions when encouraged or asked direct questions. Communicates simple messages using basic concepts but needs guidance to produce more elaborate thought (e.g. with the help of models, teacher support). When reminded, uses resources provided to execute tasks. Obtains information about situation from visual and audio cues. With support, identifies key elements and when asked, says a few words about situation with a trend of oversimplification. Uses, when reminded, explicit models or strategies that have been displayed by the teacher for the task at hand.

\section{Minimal competency development (1-2)}

Answers routine questions using basic notions. Uses simple communication strategies to compensate for unknown concepts. Demonstrates with limited representations and by following routines, partial understanding of situations. Makes sense of simple circumstances that have extensive nonverbal support. Copies from a model when working on reinvestment tasks. Asks peers and teacher for the meaning of concepts and is able to use with help a provided resource. 


\subsection{Results}

The assessment conducted prior to the simulation shows that average development of competencies is ranked acceptable (see Fig.1), which means that understanding of fundamental concept is demonstrated but capability of building on new ideas is limited and analysis is mainly restricted to obvious trends. This rather good level make sense as students are previously graduated with a master degree and most of them have already a working experience dealing with HSE matters.

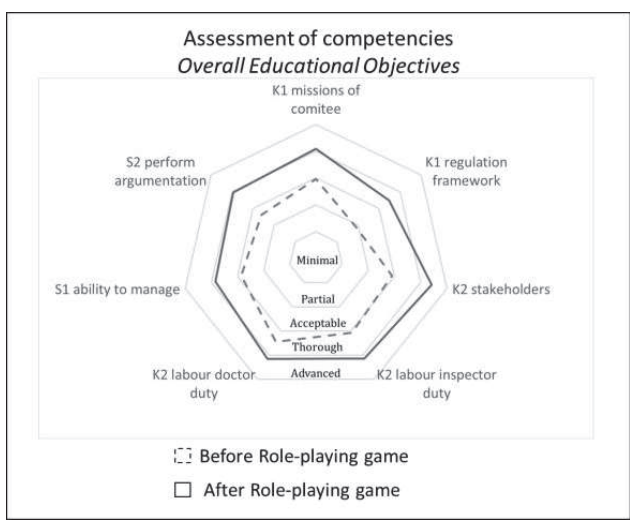

Fig. 1 Assessment of competencies: Overall educational objectives

The first area of knowledge deals with regulatory framework, purpose, role and operation of a CHSCT/CSE (see Fig.2). Prior to gameplay, acquaintance with the roles and the mission of the committee are mostly ranked Thorough (e.g. pertinent information from formal lectures are organized to support understanding of singular contexts). After the roleplaying game, a majority of students moved to an advanced level of competency. The choice of scenarios dealing with occupational accidents makes perfectly clear the range of issues that the committee should handle. It also forces to first debate and balance several aspects of problems and then infer evidence by making links among multifactorial causation of accidents. The lowest rating is associated to knowledge of regulation framework, which slightly surprised the pedagogical team considering that comprehensive materials are easily available via numerous official websites. We assumed that even if students were familiarized with CHSCT/CSE topics in their previous courses, the meager affordance of this generation for reading could be a valuable clue to enlighten that phenomenon. Nevertheless, post-simulation surveys display that knowledge of regulation has increased to upper tiers. We argue here that enactment of regulatory matters is a key part of sensemaking (Weick, 1988) since students can feel the purpose of text which can be perceived unsubstantial when taken out of context.

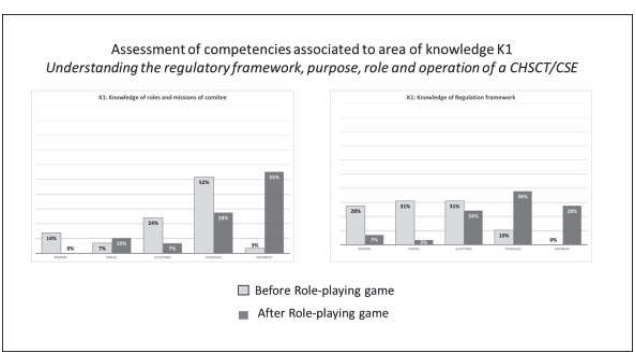

Fig. 2 Assessment of competencies: area of knowledge KI

The second area of knowledge is about understanding the expectations and visions of the participants (see Fig. 3). As expected, the knowledge of stakeholders is top graded after simulation even after a disseminated initial distribution. Here the effects of an in vivo experience are obvious as roles are not just played but incarnated by real highly skilled practitioners that closely interact. Regarding the detailed acquaintances of duties of particular roles, primary levels were once again predominantly Thorough. The ability of professionals to lively adapt and fine tune their performance, by enhancing specific aspects of their own responsibilities that are not flawlessly grasped by students is here of key importance.

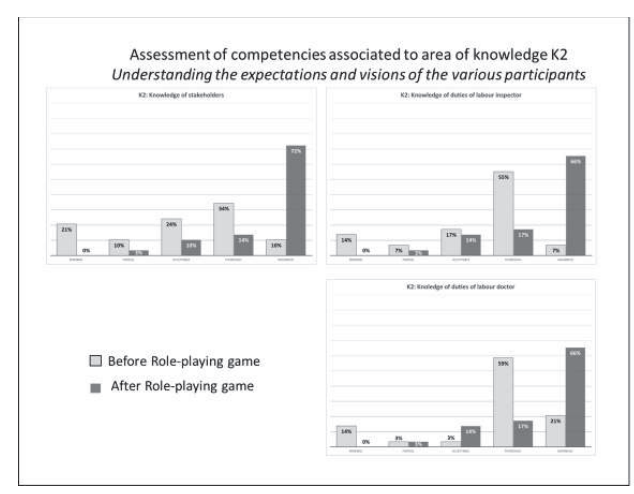

Fig.3 Assessment of competencies: area of knowledge K2

Thenceforward, ability to lead or manage a CHCST/CSE session is the first area of skills that have been assessed (see Fig.4). Preliminary appraisals are ranked for two thirds as acceptable and thorough levels, which is consistent with the fact that students are not proficient with some aspects of leading a meeting within a professional environment. Beyond formal aspects, a huge amount of material can be left unsaid that would have to be made explicit to an outsider (Jay, 1976). A significant improvement after roleplay is noticeable, 
as unlike more passive information based learning approaches, it requires the students to apply knowledge right to a practical situation (Steadman et al., 2006). Accordingly, this data confirms that simulation is appropriate for developing complex managerial capabilities (e.g. leadership, interpersonal behaviors, communication, conflict resolution...).

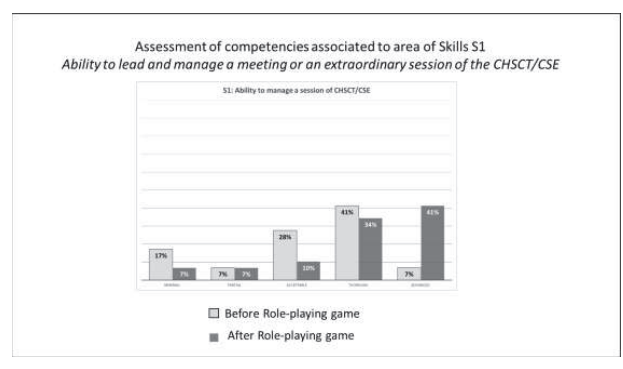

Fig.4 Assessment of competencies: area of skills S1

The second area of skills is about performing a pertinent argumentation and sustaining discussion to stand up for what one believes to be right (see Fig.5). Most students are not higher than the acceptable level which means that they can contribute in discussions on familiar topics and take turns, but they require some support to elaborate on complex ideas. They need to be driven to contribute to discussions on more complicated matters. By helping them to build links with concepts that have been taught during previous lectures and by giving instant feedback, simulation is a resourceful way to dynamically illustrate complex relationships. Students can learn a lot by trial and error without fearing for the consequences of potential mistakes and eventually gameplay gives freedom to stimulate judgment calls.

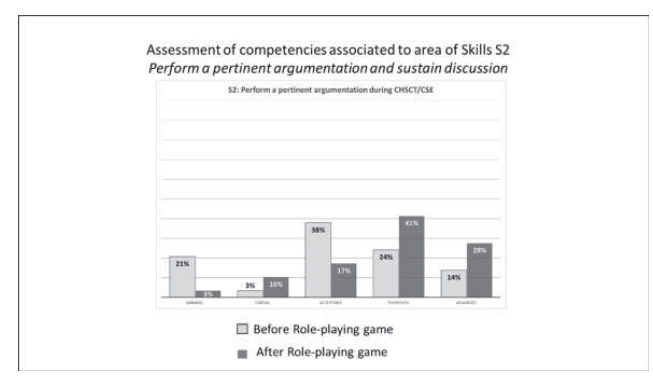

Fig.5 Assessment of competencies: area of skills S2

\section{Discussion}

Four perspectives are important in designing learning environments (Bransford, 2000). The way to which they are student centered, knowledge centered, assessment centered, and community centered will have a strong impact on the efficiency of the program.

\subsection{Student centered perspective}

The contemporary interpretation of learning is that individuals construct new knowledge and understandings based on what they already know and believe (Piaget, 1978). A students existing knowledge can either support or impede new learning (Vygotsky, 1962). Teachers must be aware of the imperfect understandings of concepts or the false beliefs that students bring with them to a given issue. In that setting of the gameplay, the group of students has been considered in terms of their current skill levels and previous experience. The importance of how new risk representation is constructed through discussion within risk analysis workshops has been discussed in previous research (Foussard \& Denis-Remis, 2014). The experience of practitioners is here crucial to promote connections between previous knowledge and current academic tasks. Furthermore, Bransford uses the metaphor of teaching conceived as constructing a bridge between the subject matter and the student. In that case student-centered teachers keep a constant eye on both ends of the bridge (Bransford, 2000). As each student learns in a different way at a specific pace, learner control is important for facilitating effective learning. Simulation-based exercise allows an increased learner control (Salas et al.,2009) and is more engaging than others classical ways of teaching.

\subsection{Knowledge centered perspective}

Facts have no meaning in themselves, so they have to be interpreted and then be given meaning which can be eventually disputed. Regarding different chosen paradigms, diverse interpretations of phenomena can be legitimated (Foucault, 1972) and so each actor contributes to weighing the influence of different theories in the discussion. A knowledge centered perspective is also decisive to design an effective learning environment. The capability to solve problems involves well-organized knowledge that is available in proper circumstances (Moreno et al., 2007). As an immersion into a real-like condition, the role-playing game is an effective tool to change the structure of knowledge from fragmented to meaningful. Representations of situations move from shallow analysis of apparent 
features to adequate concepts structured in pertinent models (Myers et al., 2009). To avoid the acquisition of disconnected sets of facts and skills, CHSCT/CSE role-playing games are the occasion to make a live synthesis of related topics helping students to grow interconnected paths within the field of safety professionalization. Activities that promote understanding and activities that promote execution of skills are properly balanced through the roleplaying game.

\subsection{Assessment centered perspective}

There are two main uses of assessment: (1) summative assessment as a measure of what students have learned after a sequence of learning activities and (2) formative assessment as basis of feedback to improve teaching and learning. (Bransford, 2000). A clear advantage of role playing game is that occasions for formal or informal feedback happen constantly. The richness of productions from both group work and individual behaviors give a bright opportunity to assess students' aptitudes to link their current actions to other parts of the curriculum and professional expectations. Role playing game also support students to get proficiencies of selfassessment (e.g. reinforcement of their own metacognition). The complexities of modern-day organizations do not allow decisions based on certainty, which means that there are no more situations that have only one certain unequivocal answer (Beck, 1992). Every decision is a risk, but simulations offer the possibility to play these risk with no consequences but the opportunity to learn more effectively by having instant feedback on their work as well as the work of their peers.

\subsection{Community centered perspective}

Contacts with practitioners have a positive impact on scholar learning since it is inspiring both to students and teachers to share working time with experimented professionals (Donovan \& Bransford, 2005). Contrary to simple marks on a test, role playing game raise standards by incorporating external participants who present challenges. A major goal of education is to fulfill the moving demands of the society; thus, teaching must produce learning packages that will be flexible enough to be valuable to future work situations. (Jarvis, 2006). To conclude, the four perspectives (i.e. student, knowledge, assessment and community) must be aligned in ways that reciprocally support one another. Promoting connections between knowledge, learning with understanding, delivering feedback and providing affinity with professional community helps both students and the pedagogical team to effectively know what is being learned.

\section{Acknowledgement}

We would like to express our gratitude to MM. Philippe BIELEC (engineer CNAMTS), Jean MARION, MD. (Occupational physician), Laurent PINA (labor inspector), Jean-Luc RUE (labor union representative) for making this CHSCT/CSE role playing game a constant success.

\section{References}

Anderson, P. H., \& Lawton, L. (2009). Business simulations and cognitive learning: Developments, desires, and future directions. Simulation \& Gaming, 40(2), 193 216.

Baruch, Y. (2006). Role-play teaching: Acting in the classroom. Management Learning, 37(1), 43-61.

Beck, U. (1992) Risk Society. London: Sage

Bloom, B. S. (1956). Taxonomy of educational objectives Vol. 1: Cognitive domain. New York: McKay, 20-24.

Bransford, J.D., with Cognition and Technology Group at Vanderbilt (1998). Designing environments to reveal, support, and expand our children's potentials. Pp. 313350 in Perspectives on Fundamental Processes in Intellectual Functioning (Vol. 1), S.A. Soraci and W. McIlvane, eds. Greenwich.

Bransford, J. D., Brown, A. L., \& Cocking, R. R. (2000). How people learn (Vol. 11). Washington, DC: National academy press.

Burns, A. C., Gentry, J. W., \& Wolfe, J. (1990). A cornucopia of considerations in evaluating the effectiveness of experiential pedagogies. Guide to business gaming and experiential learning, 253-278.

Donovan, S. \& Bransford, J. (2005). How students learn. National Research Council, National Academies Press.

Foucault, M. (1972) The Archaeology of Knowledge. London: Routledge

Foussard, C., \& Denis-Remis, C. (2014). Risk assessment: methods on purpose? International Journal of Process Systems Engineering, 2(4), 337-352.

Fripp, J. (1993). Learning Through Simulations: A Guide to the Design and Use of Simulations in Business and Education. New York: McGraw-Hill.

Greenblat, C.S. (1988). Designing Games and Simulations An Illustrated Handbook. Newbury Park, CA: Sage.

Hofstede, G. J., de Caluwe, L., \& Peters, V. (2010). Why simulation games work $\mathrm{e}$ in search of the active substance: a synthesis. Simulation \& Gaming, 41(6)

Jarvis, P. (2006). Teaching in a changing world. In The theory and practice of teaching (pp. 17-29). Routledge.

Jay, A. (1976). How to Run a Meeting. Harvard Business Review, 54(2), 43-57.

Lee, A. (2010). Simulation games: Shifting from conceptual learning to experiential learning. Blended Learning in Practice. 
Marsh, C. J. (2009). Key concepts for understanding curriculum. Routledge.

Moreno, R., and Mayer, R.E. (2007). Interactive multimodal learning environments. Educational Psychology Review, 19(3), 309-326

Myers, N. M., \& Nulty, D. D. (2009). How to use (five) curriculum design principles to align authentic learning environments, assessment, students' approaches to thinking and learning outcomes. Assessment and Evaluation in Higher Education, 34(5).

Norris, D.R. (1986). External Validity of Business Games. Simulation \& Games, vol. 17, $n^{\circ} 4$, décembre, p. 447 459.

Piaget, J. 1978 Success and Understanding. Cambridge, MA: Harvard University Press

Salas, E., Wildman, J. L., \& Piccolo, R. F. (2009). Using simulation-based training to enhance management education. Academy of Management Learning \& Education, 8(4), 559-573.

Sambell, K., McDowell, L., \& Montgomery, C. (2013). Assessment for learning in higher education. Abingdon, Oxon: Routledge.

Siemens, G. (2004). Connectivism. A Learning Theory for the Digital Age. In eLearn Space.

Steadman, R. H., Coates, W. C., Huang, Y. M., Matevosian, R.,Larmon, B. R., McCullough, L., et al. (2006). Simulation-based training is superior to problem-based learning for the acquisition of critical assessment and management skills. Critical Care in Medicine, 34: 151157

Taras, M. (2002). Using assessment for learning and learning from assessment. Assessment and Evaluation in Higher Education, 27(6), 501e510.

Tiwan, S. R., Nafees, L. \& Omkumar, K. (2014). Simulation as pedagogical tool: measurement of impact on perceived effective learning. International Journal of Management Education, 12(3), 260e270

Van Est, C., Poelman, R., \& Bidarra, R. (2011). High-level Scenario Editing for Serious Games. GRAPP, 2011, 339-346.

Van Wassenhove, W. \& Foussard, C. (2018). Professionalization in safety: A study of the professional context of a post master safety program's alumni. In Safety and Reliability-Safe Societies in a Changing World (pp. 271-278). CRC Press.

Vos, L. (2015). Simulation games in business and marketing education: How educators assess student learning from simulations. The International Journal of Management Education, 13(1), 57-74.

Vygotsky, L.S. (1962). Thought and Language. Cambridge, MA: MIT Press.
Weick, K. E. (1988). Enacted sensemaking in crisis situations. Journal of management studies, 25(4), 305317.

Wybo, J. L. \& Van Wassenhove, W. (2016). Preparing graduate students to be HSE professionals. Safety Science, 81, 25-34. 